NASATM - , \%, 207691

$$
\begin{aligned}
& \text { IN } 407 \% \\
& 081001
\end{aligned}
$$

\title{
DAMAGE CHARACTERISTICS AND RESIDUAL STRENGTH OF COMPOSITE SANDWICH PANELS IMPACTED WITH AND WITHOUT COMPRESSION LOADING
}

\author{
David M. McGowan and Damodar R. Ambur \\ NASA Langley Research Center \\ Hampton, VA 23681-0001
}

Presented at the 39th AIAA/ASME/ASCE/AHS/ASC Structures, Structural Dynamics and Materials Conference

Session No. 15 - Damage Tolerance

AIAA Paper No. $98-1783$

Long Beach, California

April 20-23, 1998 
. 


\title{
DAMAGE CHARACTERISTICS AND RESIDUAL STRENGTH OF COMPOSITE SANDWICH PANELS IMPACTED WITH AND WITHOUT A COMPRESSION LOADING
}

\author{
David M. McGowan ${ }^{*}$ and Damodar R. Ambur ${ }^{+}$ \\ NASA Langley Research Center \\ Hampton, VA 23681-0001
}

\begin{abstract}
The results of an experimental study of the impact damage characteristics and residual strength of composite sandwich panels impacted with and without a compression loading are presented. Results of impact damage screening tests conducted to identify the impact-energy levels at which damage initiates and at which barely visible impact damage occurs in the impacted facesheet are discussed. Parametric effects studied in these tests include the impactor diameter, dropped-weight versus airgun-launched impactors, and the effect of the location of the impact site with respect to the panel boundaries. Residual strength results of panels tested in compression after impact are presented and compared with results of panels that are subjected to a compressive preload prior to being impacted.
\end{abstract}

\section{Introduction}

Sandwich structures have been used extensively in stiffness-critical aircraft secondary structures. The application of sandwich structures in aircraft primary structures has been limited mainly because of undesirable moisture absorption and moisture retention characteristics, and due to an insufficient understanding of the effects of various types of damage on the structural response of sandwich structures. One such source of damage is caused by low-speed impact events that result from dropped tools during manufacturing and from runway debris and hail stones during service. Sandwich structures have the potential for improved structural efficiency and reduced manufacturing cost. This potential can be further increased by using advanced composite material systems to construct the facesheets of the sandwich structure. These advantages will make composite facesheet sandwich concepts very attractive for application to aircraft primary structures ${ }^{1,2}$ if the low-speed impact damage tolerance issues for this type of structure can be understood and resolved.

Most of the reported experimental research on the impact of sandwich plates was conducted to determine the effectiveness of different core materials, to study the influence of different facesheet materials and stacking sequences on damage resistance, to simulate impact tests using static indentation tests, to identify the damage modes due to impact, and to determine the compressive or tensile residual strength and failure modes associated with final failure. ${ }^{3-7}$ The two main damage tolerance issues associated with sandwich

\footnotetext{
Aerospace Engineer, Structural Mechanics Branch, Structures Division. Senior Member, AIAA.

$\dagger$ Assistant Head, Structural Mechanics Branch, Structures Division. Associate Fellow, AIAA

Copyright $\mathcal{C} 1998$ by the American Institute of Aeronautics and Astronautics, INC. No copyright is asserted in the United States under Title 17,U.S. Code. The U.S. Government has a royalty-free license to exercise all rights under the copyright claimed herein for government purposes. All other rights are reserved by the copyright owner.
}

structure that need to be addressed are the criterion for visible impact damage and the effect of impacting a preloaded structure on its residual strength. The existing visible impact-damage criterion for thick monolithic laminates is a 0.1 -in. dent depth or $100 \mathrm{ft}$ lbs of impact energy. This criterion has been used successfully for thick laminated structures such as wing cover panels. Sandwich structures which are proposed to be used in commercial transport aircraft fuselage or wing structures use facesheets of 8 to 16 plies $(0.04 \mathrm{in}$. to 0.08 in.) thick for which a 0.1-in. dent depth corresponds to a penetration. Reference 4 indicates that a dent depth of 0.1 in. is not an appropriate criterion for visible impact damage for 8- to 16-ply-thick facesheet sandwich plates. A 0.05 -in. dent depth has been identified as a potential visible damage criterion in Ref. 8 for relatively thick facesheet (up to 36 plies thick) sandwich structures. A similar criterion which can be used for field service inspections of transport aircraft made from thin-facesheet (8 to 12 plies thick) composite structures is needed. This criterion has to be applicable for different impactor diameters, facesheet ply stacking sequences, impactor masses, sandwich core densities, and impact sites away from the center of the panel. The results from this study may be used to establish the damage tolerance criteria for thinfacesheet sandwich structures.

The current practice for determining damage tolerance of structures with skin-stringer construction is to impact the unloaded skin laminate and then load it to failure in compression to determine its residual strength. This approach is acceptable for thick monolithic laminates such as those studied in Ref. 9 where the residual strength results for specimens impacted while preloaded and then loaded to failure do 
not differ significantly from the results obtained from compression-after-impact tests for impact-energy levels of practical interest. Similar data is needed for sandwich structures. Only Ref. 7 addresses the influence of compression preload on the residual strength of impact-damaged sandwich plates. This work, which was limited to (0/90)s graphite-epoxy facesheet sandwich beam specimens, suggested that these 3.0-in.-wide sandwich beams fail on impact while preloaded in compression at more than 40 percent of the undamaged specimen compression failure load. At the visible damage threshold, which was identified to occur for this sandwich panel at $0.88 \mathrm{ft}-\mathrm{lb}$ of impact energy $^{7}$, the ratio of the preload to the undamaged specimen failure load was determined to be 0.52 . Finite-width effects influence the impact damage characteristics, the failure strength, and the failure mode of structures. Thus, there is a need for studying the residual strength of compression-loaded sandwich plates with more practical facesheet stacking sequences and with a well quantified visible damage criterion to fully understand the behavior of preloaded sandwich structures subjected to low-speed impact in service.

The present paper presents and discusses results of a series of impact-damage screening tests and an experimental study of the compression-after-impact (CAI) and impact-under-load responses of composite facesheet sandwich panels subjected to low-speed impact damage. The impact-damage screening tests establish the impact-energy levels for damage initiation and barely visible impact damage (BVID) for the test panels used in this study. Compression tests on panels impacted using dropped-weight and airgun-propelled impactors with predetermined impact energy levels values between damage initiation and BVID levels are conducted to obtain the CAI results. Additional impact tests with the same predetermined impact-energy levels are conducted on compression-preloaded panels. Preloaded panels which survive the impact events are loaded to failure to determine their residual strength.

\section{Test Panels, Apparatus, and Conditions}

The eleven sandwich test panels of the present study were machined from a larger panel and are 5-in. wide and 10-in. long with thin composite facesheets and honeycomb core. The facesheets are 8-ply-thick laminates manufactured using Hercules, Inc. preimpregnated AS4/8552 graphite-epoxy tape and woven fabric materials. The facesheet laminate stacking sequence is $\left[\mathrm{O}_{\mathrm{f}} / 45 /-45 / 0 / 90 /-45 / 45 / \mathrm{O}_{\mathrm{f}}\right]$, where an " $\mathrm{f}$ " indicates a fabric ply. Nominal elastic properties of the two materials used in the facesheet laminates are given in Table 1. The core material is Korex $^{\boxplus}$ honeycomb core with 1/8-in. hexagonal cells and a density of $4.5 \mathrm{lb} / \mathrm{ft}^{3}$. The two facesheets are co-bonded to the core using a film adhesive. The test matrix for the study is summarized in Table 2. A diagram of a typical test panel that identifies the impact site in the panel is shown in Fig. 1. The impact-energy levels selected for the CAI and the impact-under-load tests were based on the results from the impact-damage screening tests to be presented subsequently.

As part of the test panel preparation, the core at the 5 -in.-wide loaded ends of the panels was removed to a depth of 0.5 in., and epoxy resin material was potted between the facesheets to prevent an end-brooming failure. These potted ends were machined flat and parallel to each other to assure that a uniform load is applied to the panel. For the CAI tests, the impacted facesheet of the panel was painted white so that a shadow moire interferometry technique could be used to monitor out-of-plane displacements and to observe any local response such as delamination buckling and growth at the impact sites. The moire fringe patterns were recorded using still and video photography.

For all tests, the panels were loaded in uniaxial compression in a 120-kip-capacity hydraulic test machine. A typical test setup is shown in Fig. 2. Clamped boundary conditions were provided at the loaded edges of the panels by a steel support fixture. The unloaded edges of the panels were supported with knife-edge supports. Surface strains were measured using electrical resistance strain gages. Direct-current displacement transducers (DCDT's) were used to measure out-of-plane displacements of the facesheets as well as the stroke of the test machine loading platen. The axial load applied to the panels was measured using the test machine load cell. The strain gage, DCDT, and load data were recorded using a digital data acquisition system. Data were taken at one second intervals while loading the panels to failure.

\section{Impact Damage Screening Tests}

The impact-damage screening tests were performed on samples machined from the same panel as the test panels to establish the impact-energy levels necessary to initiate damage and to inflict barely visible impact damage (BVID) in the impacted facesheet. These screening tests were performed using a dropped-weight impact apparatus ${ }^{10}$ and an airgun-launched impactor. Prior to being impacted, each sample was placed into a steel support fixture with a 4.0 -in. by 5.0 -in. opening that was secured to a rigid table. The screening tests were also conducted study the parametric effects of the impactor diameter and the location of the impact with respect to the boundaries of the samples. 
The dropped-weight impact apparatus uses a $2.5-\mathrm{lb}$ impactor with either a 0.5 -in.- (which is a common practice) or a 1.0 -in.-dia. spherical instrumented steel tup. The 1.0-in.-dia. tup is used to understand the sandwich panel impact response and damage characteristics for a larger tup diameter. The airgun uses a 0.5 -in.-dia. aluminum sphere as the impactor. The 2.5-lb dropped-weight impactor was determined to be acceptable for the impact tests based upon the analytical results presented in Fig. 3 that were generated using the analysis approach presented in Ref. 11. Maximum contact force values as a function of impactor speed are presented in Fig. 3 for a sandwich panel subjected to an impact energy of $7.0 \mathrm{ft}-\mathrm{lbs}$. The results in this figure represent different combinations of impactor mass and speed that must be used to result in a constant impact energy level. These results suggest that for impactor speeds less than $289 \mathrm{in} / \mathrm{sec}$, (i.e., impactor weight values less than $1.0 \mathrm{lb}$ ), variations in the impactor speed (or mass) do not significantly influence the contact force magnitude, which is primarily responsible for the resulting damage.

\section{Initiation of Damage in a Facesheet}

Several impacts were performed to establish the minimum impact-energy level necessary to initiate damage in the impacted facesheet of the samples. Impact-energy levels from $0.5 \mathrm{ft}-\mathrm{lb}$ to $3.0 \mathrm{ft}-\mathrm{lbs}$ with energy increments of $0.5 \mathrm{ft}-\mathrm{lb}$ were used. The initiation of damage is determined from ultrasonic C-scan inspection of the impacted facesheet. The results of a typical C-scan inspection are shown in Fig. 4 for a dropped-weight impact energy of $4.0 \mathrm{ft}-\mathrm{lbs}$ using a 0.5 in.-dia. tup. As shown in the figure, the damage area is taken to be the light-colored area in the C-scan. From similar $\mathrm{C}$-scans of the impact-damage screening samples, damage is considered to have initiated at an impact-energy level of $1.5 \mathrm{ft}$-lbs for the dropped-weight impacts using the 0.5 -in.-dia. tup and at $1.0 \mathrm{ft}-\mathrm{lb}$ for the airgun impacts. The extent of damage that resulted from the dropped-weight impacts using the 1.0-in.-dia. tup was considered to be negligible for impact-energy levels less than or equal to $3.0 \mathrm{ft}-\mathrm{lbs}$.

Measured values of the residual dent depth and the damaged area at each impact site are plotted as a function of the impact energy in Fig. 5 and Fig. 6, respectively, for dropped-weight impacts using a 0.5in.- and a 1.0-in.-dia. tup and the airgun impacts. The damaged area measurements are approximated from $\mathrm{C}$ scan inspections of the impacted samples. As seen in Fig. 5, the values of dent depth for all three impact methods are very similar to each other for impactenergy levels of up to approximately $3.0 \mathrm{ft}-\mathrm{lbs}$. The values of the damaged area are also very similar for the dropped-weight impacts with a 0.5 -in. tup and for the airgun impacts.

Contact force profiles obtained during droppedweight impacts with the 0.5 -in.- and 1.0 -in.-dia. tups at impact energy levels of 1.0 and $1.5 \mathrm{ft}-\mathrm{lbs}$ are presented in Fig. 7. Although the maximum contact force for impacts with the 1.0-in.-dia. tup are comparable to impacts with a 0.5 -in.-dia. tup, the associated damage area is much smaller. This result is due to a larger contact area of the panel experiencing a smaller contact pressure. These results suggest that the damage resulting from dropped-weight impacts with a 0.5 -in.tup and from the airgun are very similar at these low impact-energy levels and that a 0.5 -in.-dia. tup initiates damage in the facesheet at much lower values of impact energy than the 1.0-in.-dia. tup.

\section{Barely Visible Impact Damage in a Facesheet}

A series of impacts was also performed to determine the impact-energy level necessary to inflict barely visible impact damage (BVID) in the facesheet of the sandwich panels. Impact-energy levels greater than or equal to $5.0 \mathrm{ft}-\mathrm{lbs}$ were used. The criterion used for BVID in the present study is that the dent depth at the impact site should be greater than or equal to 0.05 in. As shown in Fig. 5, BVID occurred for $7.0 \mathrm{ft}-\mathrm{lbs}$ of impact energy for the dropped-weight impact using the 0.5-in.-dia. tup and the airgun impact. However, as shown in Fig. 6, the damage area resulting from the airgun impact is slightly larger than that from the dropped-weight impact. This result is also supported by the photomicrographs shown in Fig. 8. These photomicrographs are from machined and polished sections through impact sites in two samples impacted at an impact-energy level of $7.0 \mathrm{ft}-\mathrm{lbs}$. One sample was dropped-weight impacted using a 0.5 -in.-dia. tup and the other sample was airgun impacted. As seen in Fig. 8 , the damage resulting from the airgun impact is more severe than that resulting from the dropped-weight impact even though the dent depths are equal and the damage areas are similar. This observation is also supported by the results in Fig. 3 which suggest that for a given impact energy level, the contact force magnitude increases marginally as the impactor speed increases (i.e., for decreasing impactor mass). These results indicate as the impact-energy level increases, low-mass, high-speed airgun impacts can cause more extensive internal damage that may be difficult to detect visually. Thus, using dent depth only as a criterion for measuring the severity of impact damage in sandwich structure may not always be reliable.

Effect of impactor diameter on BVID. Due to restrictions in the impact test machine, the largest 
impact-energy level that can be attained with the dropped-weight apparatus using the 2.5-lb impactor used in this study is $12.7 \mathrm{ft}-\mathrm{lbs}$. The residual dent depth at this impact-energy level for an impact using the 1.0in.-dia. tup is 0.0425 in., which is slightly less than the 0.05 -in. criterion used in this study. An impact at the same level of $12.7 \mathrm{ft}$-lbs with the 0.5 -in.-dia. tup resulted in impactor penetration through the facesheet. These results, as shown in Fig. 5, indicate that, as the impact-energy level is increased to a value greater than $3 \mathrm{ft}-\mathrm{lbs}$, the tup diameter does influence the dent depth resulting in a significant difference in the impactenergy values at which visible damage occurs.

Contact-force profiles for dropped-weight impacts with the 0.5 -in.- and 1.0-in.-dia. tups at impact-energy levels of 6.0 and $7.0 \mathrm{ft}-\mathrm{lbs}$ are presented in Fig. 9. Although the maximum contact force value for the 0.5in.-dia. tup remains relatively constant for these energy levels, the dent depth increases from approximately 0.04 in. to 0.05 in. (see Fig. 5). Similarly, the maximum contact force value for the 1.0-in.-dia. tup remains nearly constant while the dent depth increases from 0.0055 in. to 0.007 in. Furthermore, although the maximum values of contact force for the impacts using the 1.0-in.-dia. tup are higher than those for the impacts using the 0.5-in.-dia. tup, the values of dent depth and damage area are lower for the larger diameter tup. Photomicrographs of machined and polished sections through the impact sites of two samples impacted at an impact-energy level of $6.0 \mathrm{ft}$-lbs using the 0.5 -in.- and 1.0-in.-dia. tups are shown in Fig. 10. As shown in this figure, the damage states resulting from the two impacts are very different. Significant internal damage resulted from the impact using the 0.5 -in.-dia. tup, while only minor damage in the form of a delamination between the central $0^{\circ}$ and $90^{\circ}$ plies resulted from the impact using the 1.0-in.-dia. tup. This result further illustrates that tup diameter does affect the dent depth and it is, in addition to the contact force magnitude, an important parameter in determining the threshold impact-energy level for BVID in this sandwich structure.

\section{Effect of Impact Location}

Two dropped-weight impacts were performed to gain insight into the effects of the location of the impact with respect to the boundaries of the sample. The tests were performed using the 0.5 -in. tup and an impactenergy level of $7.0 \mathrm{ft}$-lbs. Impact sites shown in Fig. 11 that were $0.75 \mathrm{in}$. and $2.5 \mathrm{in}$. inward from the boundary of the fixture were selected. The values of the residual dent depth for the two impacts sites are 0.0415 in. and 0.0455 in., respectively, and the values of the damage area are $0.2155 \mathrm{in}^{2}$ and $0.2355 \mathrm{in}^{2}$, respectively. The contact force profiles for the two impacts are shown in
Fig. 12. As shown in the figure, the two contact force profiles have very similar duration and magnitude. Photomicrographs taken of the two impact sites also indicate that the damage states of the two impact sites are very similar. These results indicate that the location of the impact in sandwich structure with respect to the boundaries of the structure does not significantly influence the damage state produced by the impacts and that the impact event is very local. ${ }^{11}$

\section{Impact-Energy Levels for Residual Strength Tests}

Ten 5.0-in.-wide by 10.0-in.-long sandwich panels were impacted for residual strength testing. To allow for a direct comparison of results from the airgun impacts which use a 0.5 -in.-dia. sphere, only the 0.5 in.-dia. tup was used for the dropped-weight impacts for these tests. Based upon the results of the impactdamage screening tests, the CAI panels were impacted at energy levels of $1.5 \mathrm{ft}-\mathrm{lbs}, 4.0 \mathrm{ft}-\mathrm{lbs}$, and $7.0 \mathrm{ft}-\mathrm{lbs}$ using the dropped-weight impactor and at $1.1 \mathrm{ft}-\mathrm{lbs}, 3.8$ $\mathrm{ft}-\mathrm{lbs}, 4.2 \mathrm{ft}-\mathrm{lbs}$, and $6.9 \mathrm{ft}-\mathrm{lbs}$ using the airgun impactor. The minimum and maximum impact-energy levels represent the thresholds for damage initiation and BVID in the impacted facesheet. The variations in the impact-energy levels for the airgun impacts occur due to slight fluctuations in the speed of the airgunlaunched impactor. The impact-energy level used for the preloaded panels was selected to be $7.0 \mathrm{ft}-\mathrm{lbs}$, which corresponds to a BVID. These impacts were performed using the airgun only. The procedure for establishing the preload value for the impact-under-load panels is discussed in a later section.

\section{Residual Strength Characterization}

Results from residual strength tests of eleven sandwich panels are presented in this section. Panel 1 was an undamaged control panel. Results for CAI panels impacted using a dropped-weight impactor with a 0.5-in.-dia. tup and an airgun impactor are compared. Due to a technical problem, the airgun impactor did not strike the center of Panel 6. This impact was repeated for Panel 7, and Panel 6 was tested without knife-edge supports along the unloaded edges to investigate the effect of boundary conditions on the structural response of the panel. The effect of applying a compressive preload prior to impacting the panel is also discussed in this section. The panel numbering and the type of test performed on each panel is given in Table 2 .

\section{Compression After Impact (CAI) Tests}

Typical load-end-shortening curves for Panels 1 and 5 through 8 are shown in Fig. 13. The failure load for each panel is shown as a filled circle. A comparison 
of the data of Panels 5 - 8 with that of Panel 1 indicates that the presence of impact damage has no effect on the global axial stiffness of the panels. The load-endshortening data for Panels 1 - 4 also support this finding.

Typical axial surface strain results that show the redistribution of load around the impact damage location are shown in Fig. 14 for Panels 1 through 4 and in Fig. 15 for Panels 1 and 5 through 8. In these figures, far-field strains at the location marked SG A are plotted using solid lines, and strains at a location adjacent to the impact site (SG B) are plotted using dashed lines. As shown in Fig. 14, Panels 3 and 4 exhibited local strain concentrations (ratio of SG B to SG A data) near the impact site. Each panel exhibited a maximum measured strain concentration of 2.54. Panel 2 did not exhibit any local strain concentration near the impact site. Panels 5, 7, and 8 exhibited maximum measured strain concentrations of $1.61,2.83$, and 2.62 , respectively. The strain concentrations exhibited by the airgun-impacted panels were slightly higher than those for the dropped-weight-impacted panels for a given impact energy level. These results support the observed severity of the damage conditions for airgun impacts as compared to that for dropped-weight impacts.

Panel 6 was tested without knife-edge supports, and it exhibited a strain concentration of 3.55 just prior to failure. However, DCDT measurements normal to the undamaged facesheet indicate that bending occurred just prior to failure in a direction that increased the compressive strain in the impacted facesheet. Thus, the absence of knife-edge supports appears to only have affected the panel response just prior to failure. The global axial stiffness of the panel was not affected and the failure load was very close to that of Panel 7 .

The failure mode for all impacted panels was a compression failure across the width of the panel passing through the impact site. The failure mode for Panel 6 is shown in Fig. 16. This figure also shows the deformation of Panel 6 that contributed to the increased strain concentrations at the impact site. The failure loads for all panels tested are plotted in Fig. 17 as a function of the impact energy level at which each panel was impacted. In Fig. 17, the experimental results for the undamaged and CAI panels (1 through 8$)$ are plotted as open symbols, and the results for the impactunder-load panels ( 9 through 11) are plotted as the filled circles. Polynomial curves fitted through the data for panels 1 through 8 are also shown to assist in identifying trends in the data. There is only a 5.1 percent difference in the failure loads for the panels impacted with the dropped-weight apparatus as compared to those impacted with the airgun at the impact energy level at which damage initiates. However, as the impact energy level is increased to a level that produces BVID, this difference increases to 13.7 percent, with the airgun-impacted panels failing at lower loads. This result is consistent with the results of the impact-damage screening tests. The damage associated with airgun impacts was shown to be more severe than that associated with dropped-weight impacts as the impact energy level is increased.

\section{Impact Under Load Tests}

The effect of applying a compressive preload to a panel before impacting it was also investigated in the present study. Panels 9 through 11 were first loaded to a predetermined load level and then impacted with the airgun-launched projectile at impact energy levels of $7.2,7.5$, and $7.1 \mathrm{ft}-\mathrm{lbs}$. Again, the variation in the impact energy levels occurs due to variations in the speed of the airgun-launched projectile.

The value of the preload was selected based upon the design stress for the original panel from which the test panels were machined. The original panel was designed to study the effect of discrete-source damage on this sandwich structure. The design stress for this panel, which would correspond to a design limit stress, was $14.4 \mathrm{ksi}$. This stress corresponds to a load of 8,500 lbs for the present test panels. Therefore, Panel 9 was loaded to $8,500 \mathrm{lbs}$ before being impacted. Since Panel 9 did not fail at impact, the preload value was increased to $12,800 \mathrm{lbs}$ for Panel 10 . This 150 percent increase represents the difference between design limit and design ultimate stress. Panel 10 did not fail at impact. In an attempt to establish a narrow load and strain range at which failure would occur at impact, Panel 11 was preloaded to $18,000 \mathrm{lbs}$. This preload is $200 \mathrm{lbs}$ less than that at which Panel 8 (CAI panel airgun impacted at $6.9 \mathrm{ft}$-lbs impact energy) failed. Panel 11 failed at impact. This result indicates that there is a threshold value of strain in the loaded panels above which impact at an energy level high enough to cause BVID will result in failure. A summary of the preload value, impact energy level and final failure load for Panels 9 through 11 is presented in Table 2. These results also suggest that for the BVID criterion chosen in this study, the sandwich panel can support approximately 47 percent of its undamaged failure load before failing when subjected to airgun impact.

Load-end-shortening curves for Panels 8 through 11 are presented in Fig. 18. The failure load for each panel is indicated by a filled circle. Panel 8 is included to determine if differences in response occur between a CAI panel and an impact-under-load panel when both panels are impacted with the same impact-energy level. These data indicate that the effect of impacting compressive preloaded panels on the global axial stiffness of the panels was negligible. 
Axial surface strain results for Panels 8 through 11 measured at locations away from the impact site and adjacent to the impact site are shown in Fig. 19 and Fig. 20, respectively. The results in Fig. 19 indicate that the far-field response of the impacted facesheet is relatively insensitive to the order in which the panel is impacted and loaded. However, the results in Fig. 20 indicate that the local response of the impacted facesheet is sensitive to this order. Upon impact, Panel 9 exhibited a 54 percent increase in the strain adjacent to the impact site (approximately $1,200 \mu$-in/in), and Panel 10 exhibited a 43 percent increase (approximately $1,500 \mu$ in/in). Panel 11 failed upon impact at a strain level of approximately $4,900 \mu$-in/in. The strain at this location in Panel 8 just prior to failure was $11,600 \mu$-in/in, which is more than twice as large as that in Panel 11 when it was impacted. This result also supports the conclusion that there is a threshold value of strain in the loaded panels above which impact at an energy level high enough to cause BVID will result in failure. Although this strain threshold is larger than the relatively low design strain for the present sandwich panels, a more aggressive structural design could easily require design strain values that approach this threshold. The existence and value of this threshold must therefore be taken into account when using residual strength results determined from CAI tests to design aircraft structures.

\section{Concluding Remarks}

The present paper describes the results of impactdamage screening tests and an experimental study of the compression-after-impact (CAI) and impact-underload responses of composite facesheet sandwich panels subjected to low-speed impact damage. These panels were 5-in.-wide and 10-in. long with thin composite facesheets co-bonded to honeycomb core. Droppedweight impactors with 0.5 -in. and 1.0 -in.-dia. steel tups and an airgun-launched impactor (0.5-in.-dia. aluminum sphere) were used in the present study.

A series of impact-damage screening tests was conducted to determine the impact-energy levels at which damage initiates and at which barely visible impact damage (BVID) occurs in the impacted facesheet. The criterion used for BVID in the present study is a residual dent depth at the impact site greater than or equal to $0.05 \mathrm{in}$. This criterion seems to be practical for both thick-facesheet sandwich panels used in Ref. 8 and the thin-facesheet sandwich panels used in the present study. Results of these tests indicate that damage initiates and BVID occurs at lower impact energy levels for dropped-weight impacts with a 0.5in.-dia. tup than it does for impacts with a 1.0-in.-dia. tup. Results also indicated that the damage states resulting from dropped-weight impacts with a 0.5-in.dia. tup and the airgun were very similar to each other for low values of impact energy. As the impact-energy level was increased to that which causes BVID, the airgun impacts caused more extensive internal damage than the dropped-weight impacts even though the dent depths for the two methods of impact were very similar. This result suggests that using dent depth only as a measure of the extent of damage in an impacted structure may not always be reliable. Finally, droppedweight impact test results with a 0.5 -in.-dia. tup in the center and near the edge of a panel suggest that the dent depths, damage area, and contact force profiles for each impact are very similar to each other, indicating the local nature of the impact response.

Tests of CAI panels impacted with 0.5-in.-dia. dropped-weight and airgun impactors were conducted using impact-energy levels determined from the impactdamage screening tests. Results of the CAI tests indicate that the global response of the panels was not affected by the presence of impact damage. The residual strength of the panels impacted using both methods was similar to each other for low-energy-level impacts. However, as the impact energy level was increased, the residual strength of the airgun-impacted panels was less than that of the dropped-weightimpacted panels. This result is consistent with the results from the impact-damage screening tests.

Compression tests were also conducted on panels that were preloaded prior to being impacted with the airgun. The impact energy level used was that required to inflict BVID in the impacted facesheet. Preloaded panels that survived the impact events were loaded to failure to determine their residual strength. Results of these tests indicate that, for the BVID criterion used in this study, the global response of the panels was insensitive to the order in which the panel is impacted and loaded. However, the local response near the impact site is very sensitive to this order. Furthermore, these tests indicated that there is a threshold value of strain in the preloaded panels above which impact at an energy level high enough to cause BVID will result in failure. Therefore, to allow for more aggressive designs that utilize composite facesheet sandwich structure, the existence and value of this strain threshold must be taken into account when using residual strength results determined from CAI tests to design aircraft structures.

\section{References}

${ }^{1}$ Smith, P. J.; Ilcewicz, L. B.; and Olson, J. T.: Advanced Technology Composite Fuselage. Proceedings of the Fifth NASA/DoD/ARPA Advanced 
Composites Technology Conference, NASA CP-3294, 1995, pp. 1-31.

${ }^{2}$ Avery, W. B.; Flynn, B. W.; Hanson, C. T.; Scholz, D. B.; Murphy, D. P.; Carberry, D. J.; Dopker, B.; Williams, A. M.; and Ilcewicz, L. B.: Design and Structural Development of a Composite Fuselage Keel Panel. Proceedings of the Fifth NASA/DoD/ARPA Advanced Composites Technology Conference, NASA CP-3294, 1995, pp. 463-496.

${ }^{3}$ Gottesman, T.; Bass, M.; and Samuel, A.: Criticality of Impact Damage in Composite Structures. Proceedings of the Sixth International Conference on Composite Materials, London, 1987, pp. 3.27-3.35.

${ }^{4} \mathrm{Rix}, \mathrm{C}$.; and Saczalski, T.: Damage Tolerance of Composite Sandwich Panels. Proceedings of the Eighth International Conference on Composite Materials, Honolulu, 1991, pp. 3-I-1 to 3-I-10.

${ }^{5}$ Tsang, P.H.W.; and Dugundji, J.: Damage Resistance of Graphite-Epoxy Sandwich Panels Under Low Speed Impacts. Journal of the American Helicopter Society, Vol. 37, No. 1, January 1992, pp. 75-81.

${ }^{6}$ Ferri, R.; and Sankar, B.V.: A Comparative Study on the Impact Resistance of Composite Laminates and Sandwich Panels. Proceedings of the American Society for Composites - Ninth Technical Conference, Newark, DE, September 20-22, 1994, pp. 482-490.
${ }^{7}$ Rhodes, M. D.: Impact Fracture of Composite Sandwich Structures. AIAA Paper No. 75-748, May 1975.

${ }^{8}$ McGowan, D. M. and Ambur, D. R.: Damage Tolerance Characteristics of Composite Fuselage Sandwich Structures With Thick Facesheets, NASA TM 110303, Feb. 1997.

${ }^{9}$ Williams, J. G.; Anderson; M. S.; Rhodes, M. D.; Starnes, J. H., Jr.; and Stroud, W. J.: Recent Developments in the Design, Testing and ImpactDamage Tolerance of Stiffened Composite Panels. Fibrous Composites in Structural Design (Proceedings of Fourth Conference on Fibrous Composites in Structural Design), Plenum Press, New York, NY, 1980, pp. 259-291.

${ }^{10}$ Ambur, D. R.; Prasad, C. B.; and Waters, W. A.: An Internally Damped, Self-Arresting Dropped Weight Apparatus for Studying the Low-Speed Impact Response of Composite Structures. Journal of Experimental Mechanics, Vol. 33, No. 1, March 1995, pp. 64-69.

"Ambur, D. R. and Cruz, J. R.: Low-Speed Impact Response Characteristics of Composite Sandwich Panels. AIAA Paper No. 95-1460, April 1995.

Table 1. Nominal elastic properties of AS4/8552 graphite-epoxy pre-impregnated tape and cloth materials.

\begin{tabular}{cccccccccc}
\hline \hline Material & $\mathrm{E}_{11}, \mathrm{msi}$ & $\mathrm{E}_{22}, \mathrm{msi}$ & $\mathrm{G}_{12}, \mathrm{msi}$ & $\mathrm{G}_{13}, \mathrm{msi}$ & $\mathrm{G}_{23}, \mathrm{msi}$ & $v_{12}$ & $v_{13}$ & $v_{23}$ & Ply thickness, in. \\
\hline Tape & 16.3 & 1.36 & 0.766 & 0.766 & 0.52 & 0.32 & 0.32 & 0.40 & 0.0073 \\
Fabric & 8.70 & 8.70 & 0.766 & 0.766 & 0.52 & 0.046 & 0.32 & 0.40 & 0.0078 \\
\hline \hline
\end{tabular}

Table 2. Test matrix and summary of failure loads.

\begin{tabular}{ccccccc}
\hline \hline Panel & $\begin{array}{c}\text { Impact energy, } \\
\mathrm{ft}-\mathrm{lbs}\end{array}$ & Type of impact & $\begin{array}{c}\text { Dent depth, } \\
\text { in. }\end{array}$ & $\begin{array}{c}\text { Damage area, } \\
\text { in }^{2}\end{array}$ & $\begin{array}{c}\text { Load at impact, } \\
\text { lbs }\end{array}$ & $\begin{array}{c}\text { Failure load, } \\
\text { lbs }\end{array}$ \\
\hline 1 & Undamaged & - & - & - & - & 38,500 \\
2 & 1.5 & Dropped weight & 0.0030 & 0.0285 & - & 26,200 \\
3 & 4.0 & Dropped weight & 0.0135 & 0.0873 & - & 22,500 \\
4 & 7.0 & Dropped weight & 0.0501 & 0.2565 & - & 20,700 \\
5 & 1.1 & Airgun & 0.0022 & 0.0160 & - & 27,600 \\
$6^{*}$ & 3.8 & Airgun & 0.0210 & 0.1140 & - & 20,800 \\
7 & 4.2 & Airgun & 0.0230 & 0.1781 & - & 20,400 \\
8 & 6.9 & Airgun & 0.0450 & 0.3010 & - & 18,200 \\
9 & 7.2 & Airgun & - & - & 8,500 & 18,300 \\
10 & 7.5 & Airgun & - & - & 12,800 & 17,200 \\
11 & 7.1 & Airgun & - & - & 18,000 & 18,000 \\
\hline \hline
\end{tabular}

${ }^{*}$ Projectile did not strike center of panel. Impact was repeated on Panel 7. Panel 6 was tested without edge supports. 


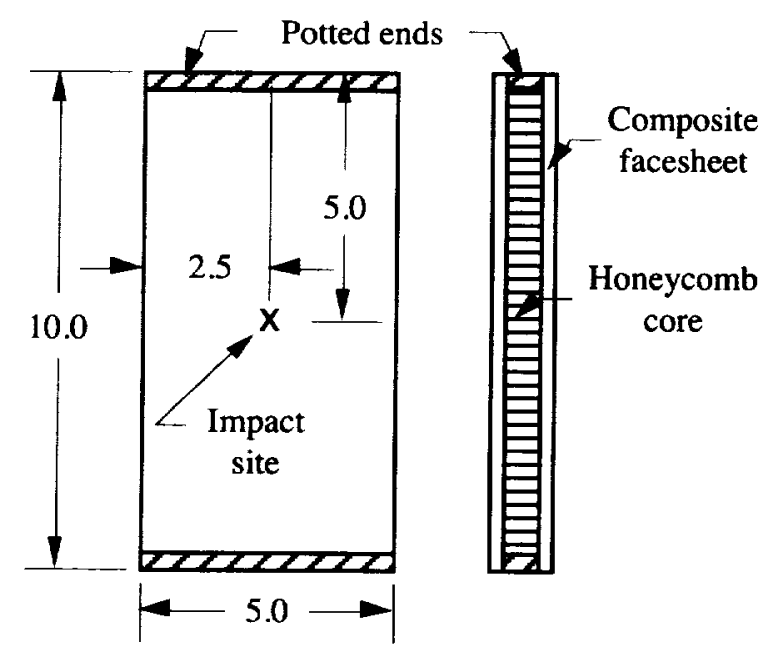

Fig. 1 Schematic diagram of a typical test specimen. (Dimensions are in inches)

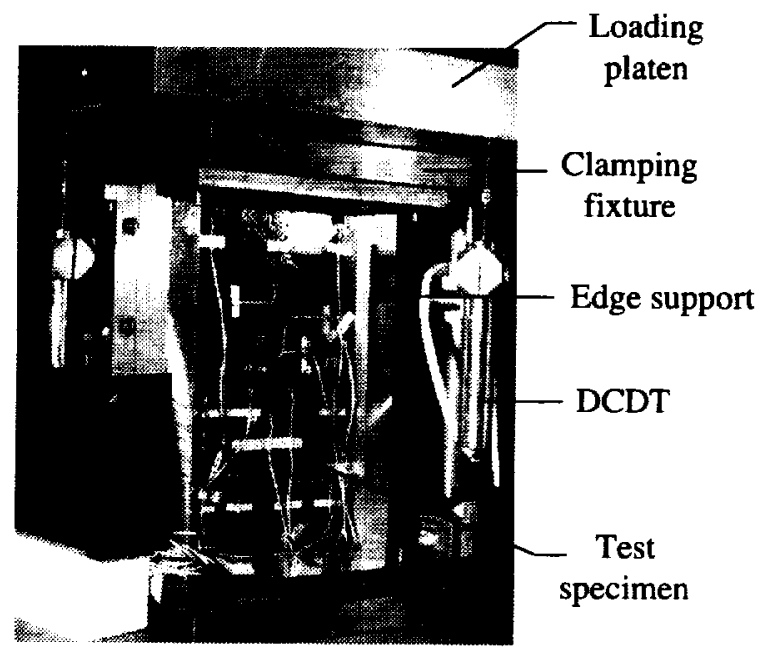

Fig. 2 Typical test set-up.

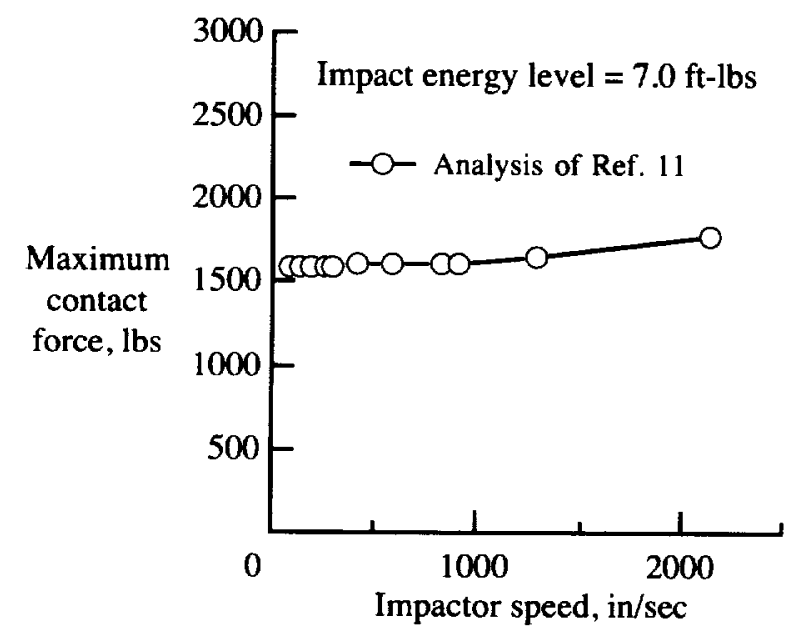

Fig. 3 Maximum contact force as a function of impactor speed for the present sandwich panels.

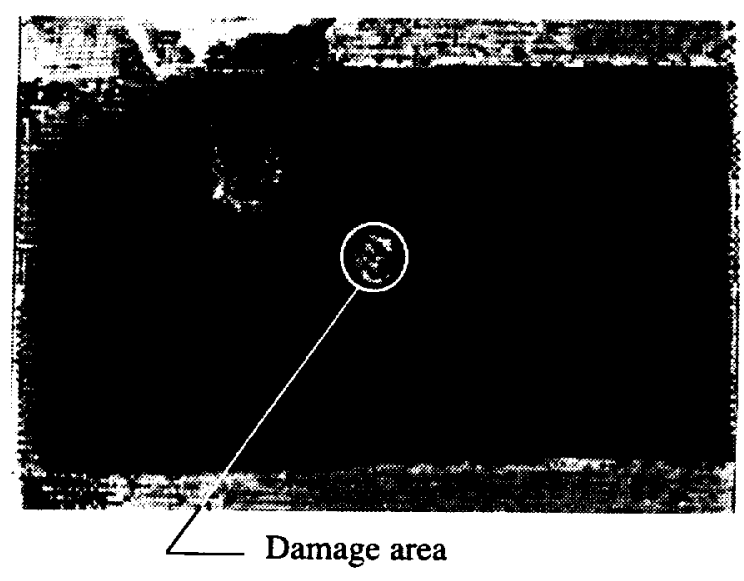

Fig. 4. Typical C-scan results forPanel 3 droppedweight impacted at $4.0 \mathrm{ft}$-lbs using a 0.5 -in.diameter tup.

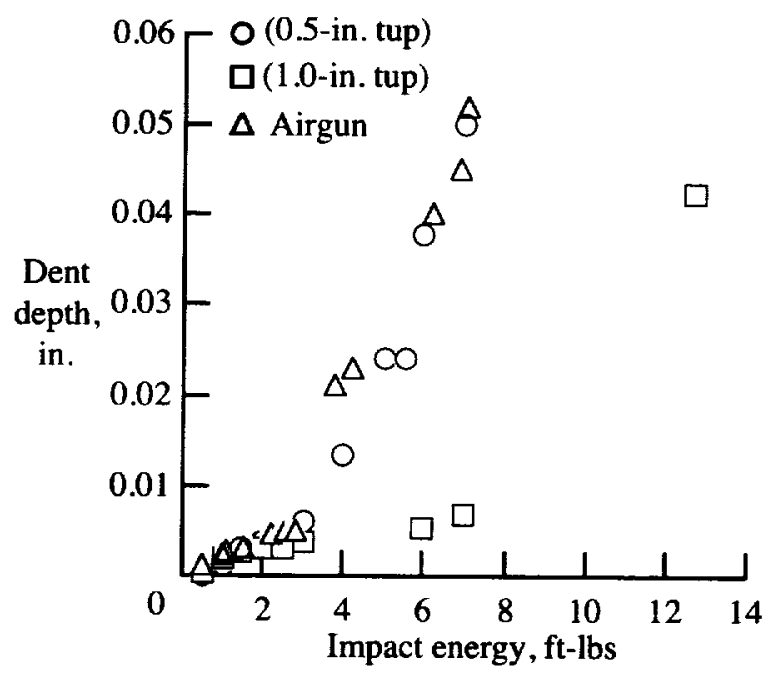

Fig. 5. Residual dent-depth values at each impact site.

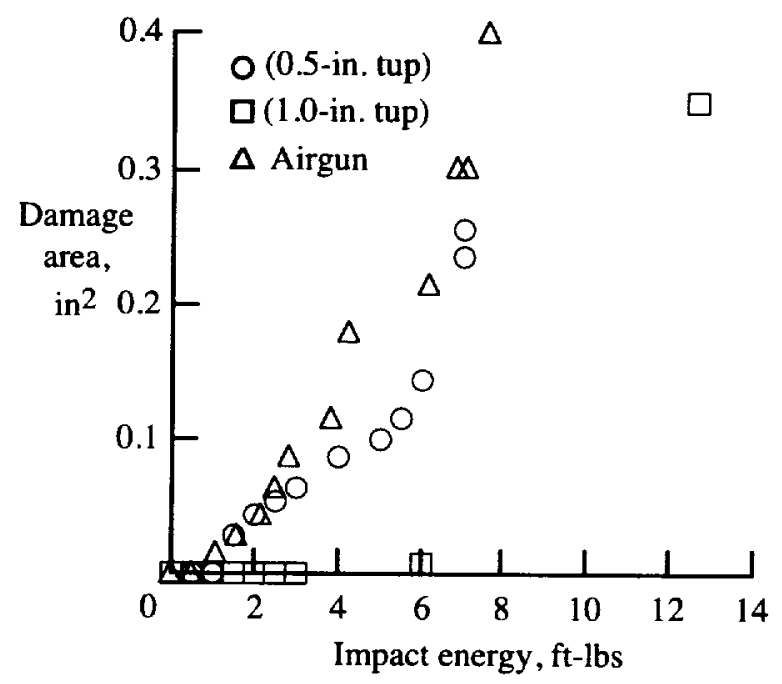

Fig. 6. Damaged area values at each impact site. 


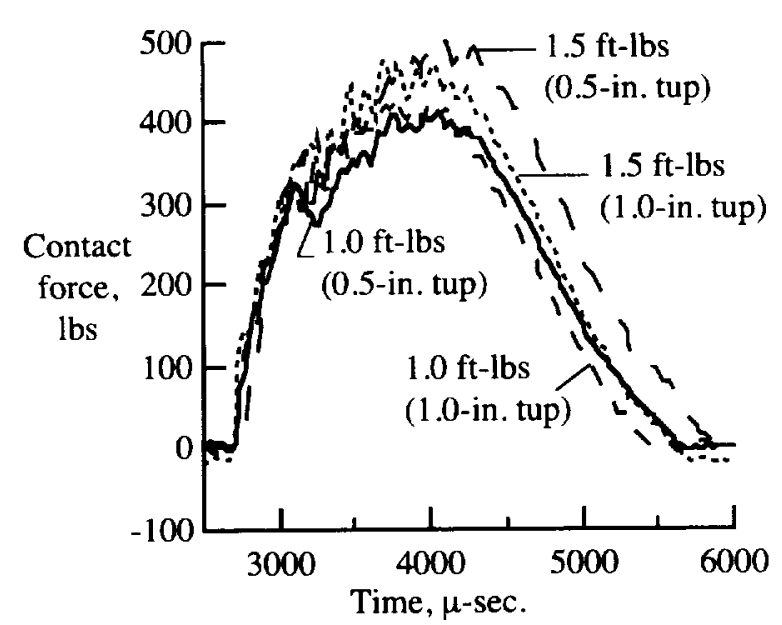

Fig. 7. Contact force profiles for dropped-weight impacts at 1.0 and $1.5 \mathrm{ft}$-lbs of impact energy.

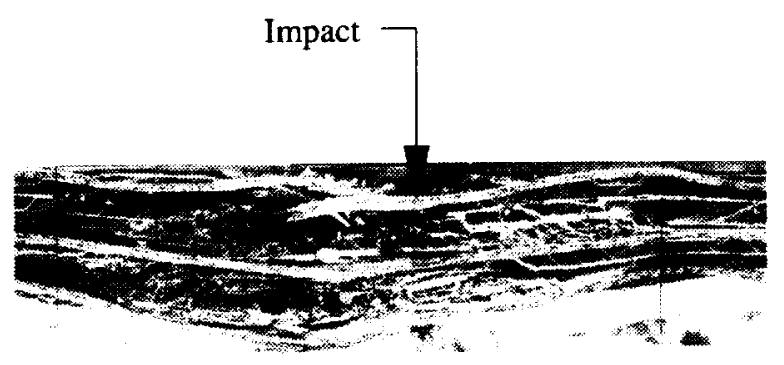

(a) dropped-weight, 0.5 -in.-diameter tup, $7.00 \mathrm{ft}$-lbs of impact energy (32x magnification)

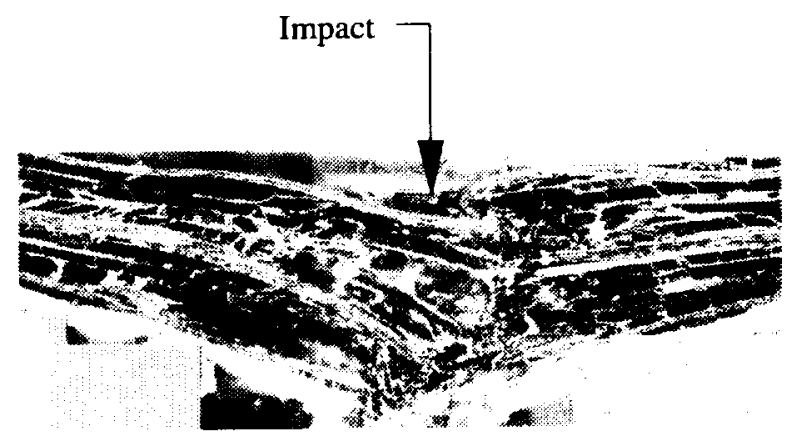

(b) airgun, $7.10 \mathrm{ft}-\mathrm{lbs}$ of impact energy (32x magnification)

Fig. 8. Photomicrographs comparing damage state resulting from dropped-weight and airgun impacts.

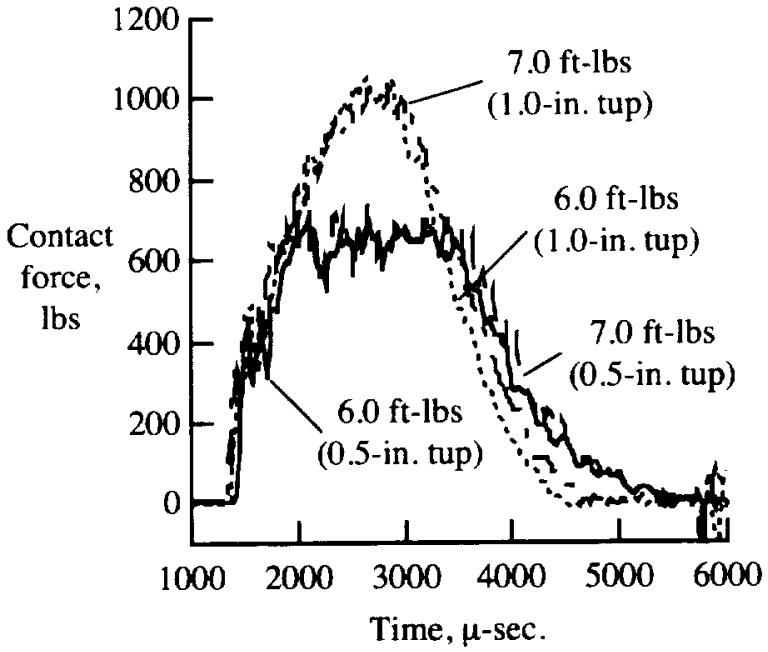

Fig. 9. Contact force profiles for dropped-weight impacts at 6.0 and $7.0 \mathrm{ft}-\mathrm{lbs}$ of impact energy.

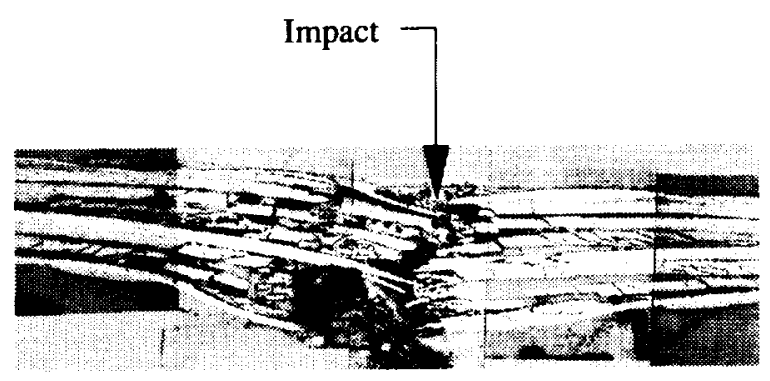

(a) 0.5-in.-diameter tup, $6.0 \mathrm{ft}$-lbs of impact energy ( $32 \mathrm{x}$ magnification)

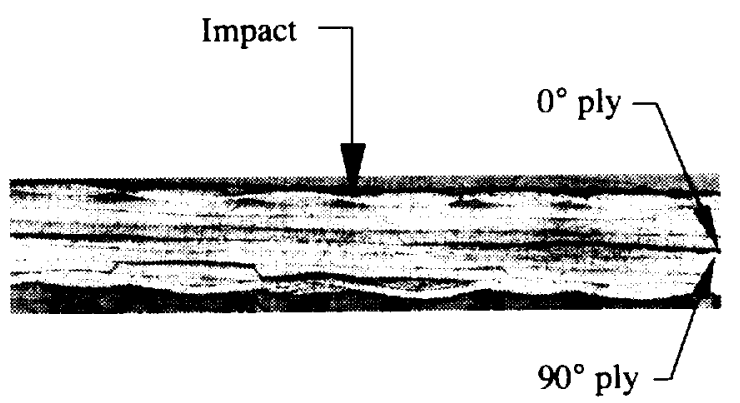

(b) 1.0-in.-diameter tup, $6.0 \mathrm{ft}$-lbs of impact energy (25x magnification)

Fig. 10. Photomicrographs comparing damage state resulting from dropped-weight impacts using a 0.5 -in.- and a 1.0 -in.-diameter tup. 


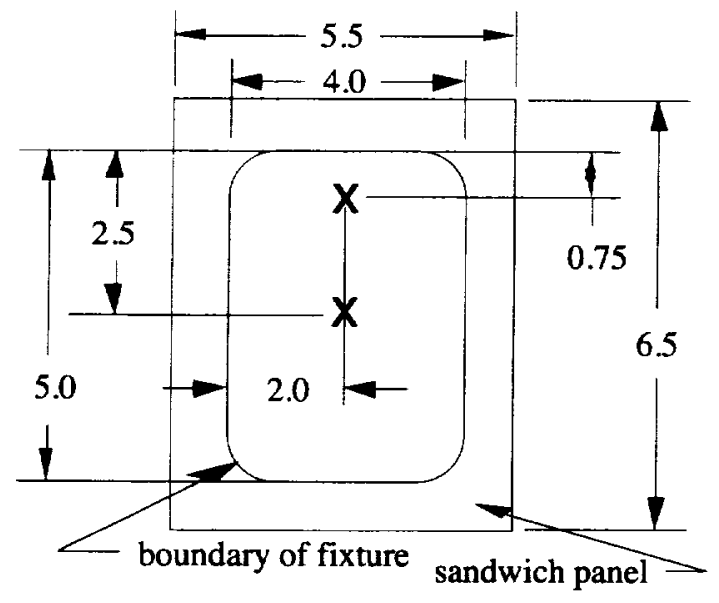

Fig.11. Locations of impacts to study boundary effects on impact response (dimensions are in inches).

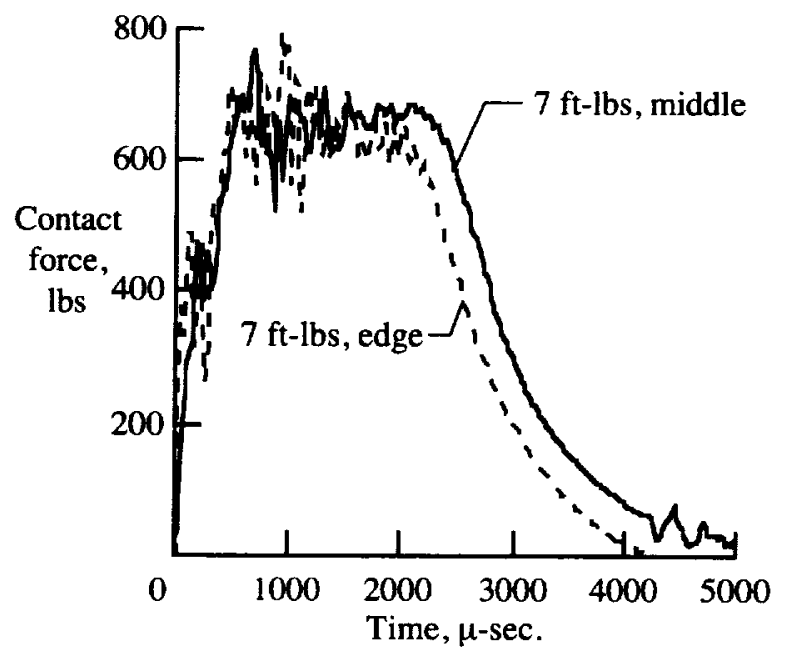

Fig.12. Effect of impact location on contact force profiles for dropped-weight impacts.

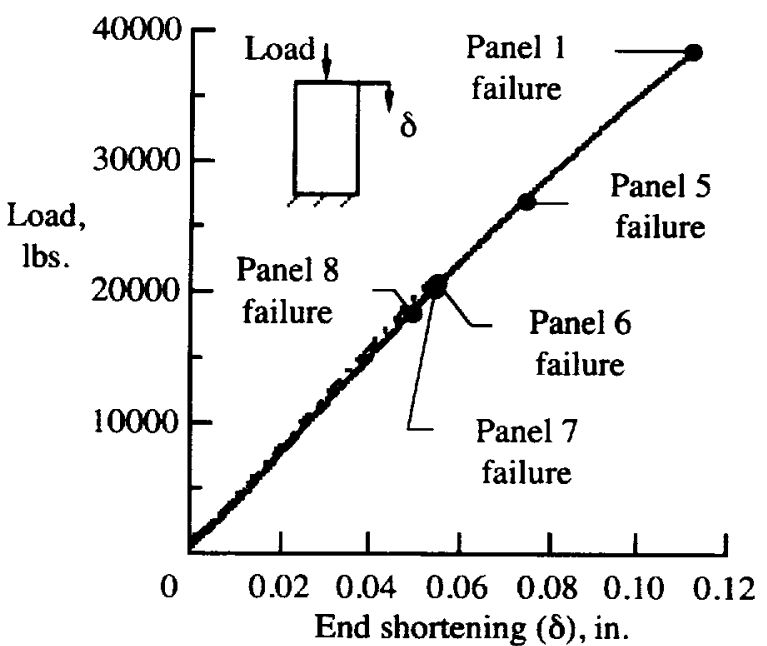

Fig.13. Load-end shortening response for Panels 1 and 5-8.

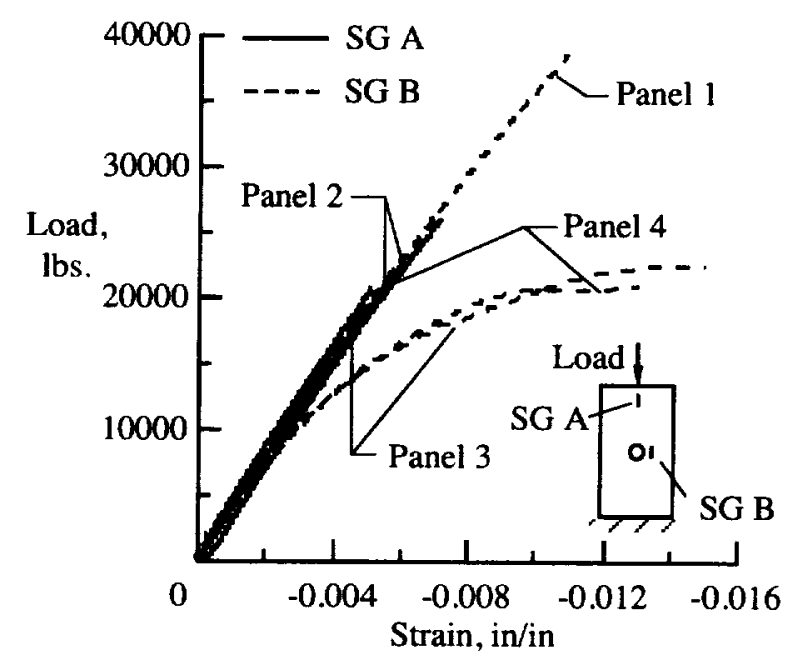

Fig.14. Axial surface strain results for Panels 1 - 4 .

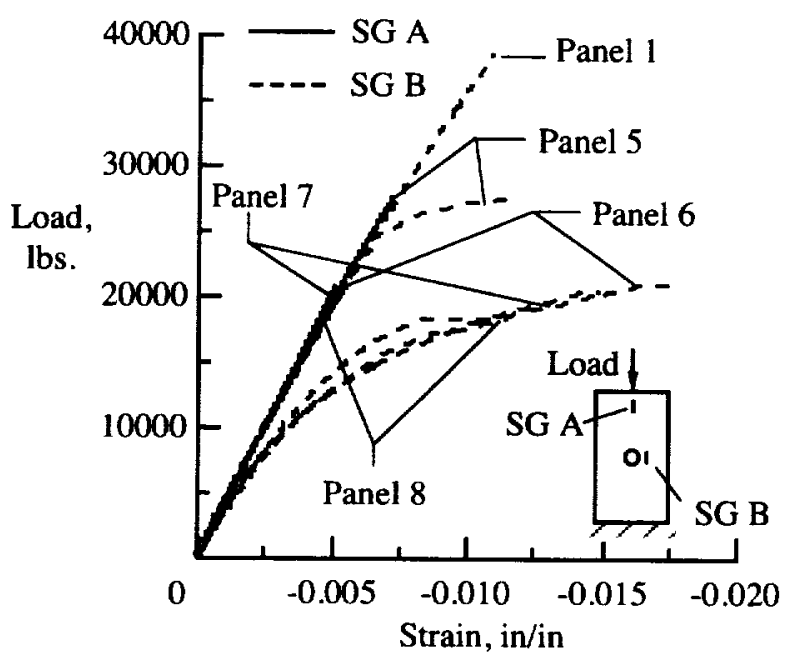

Fig.15. Axial surface strain results for Panels 1 and 5-8.

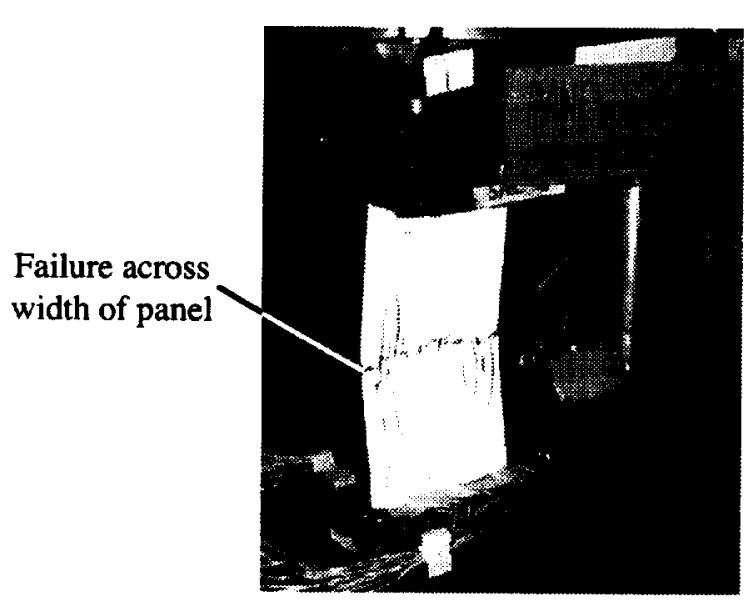

Fig.16. Failed Panel 6. 


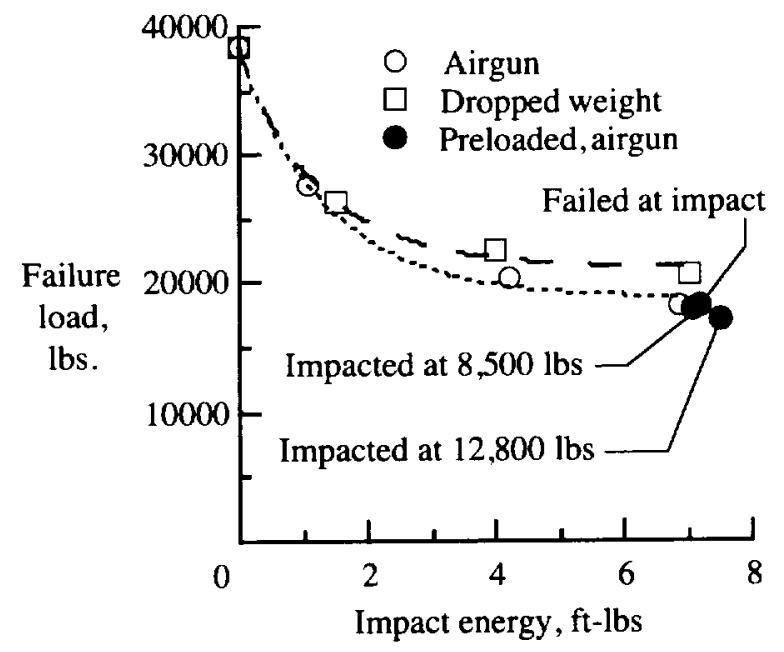

Fig.17. Failure loads as a function of impact energy.

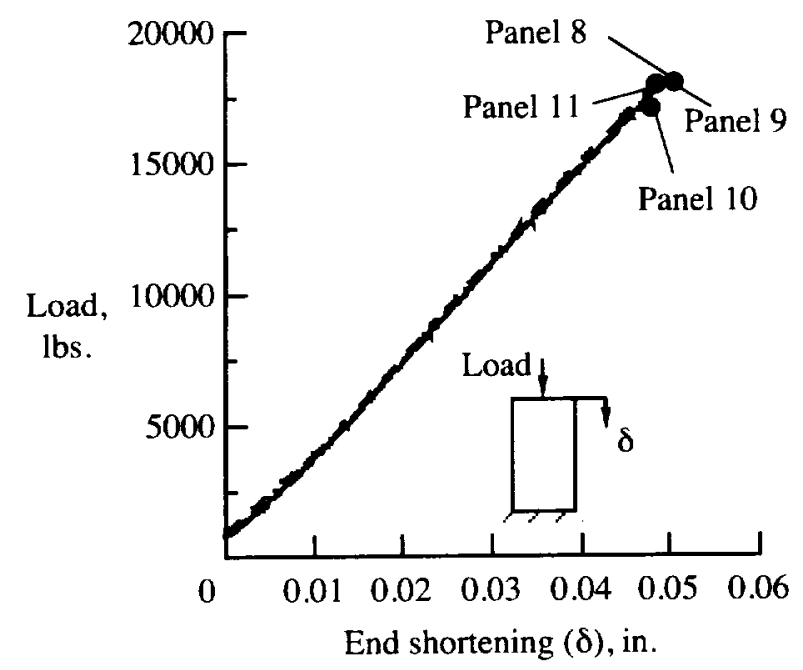

Fig.18. Load-end shortening response for Panels 8-11.

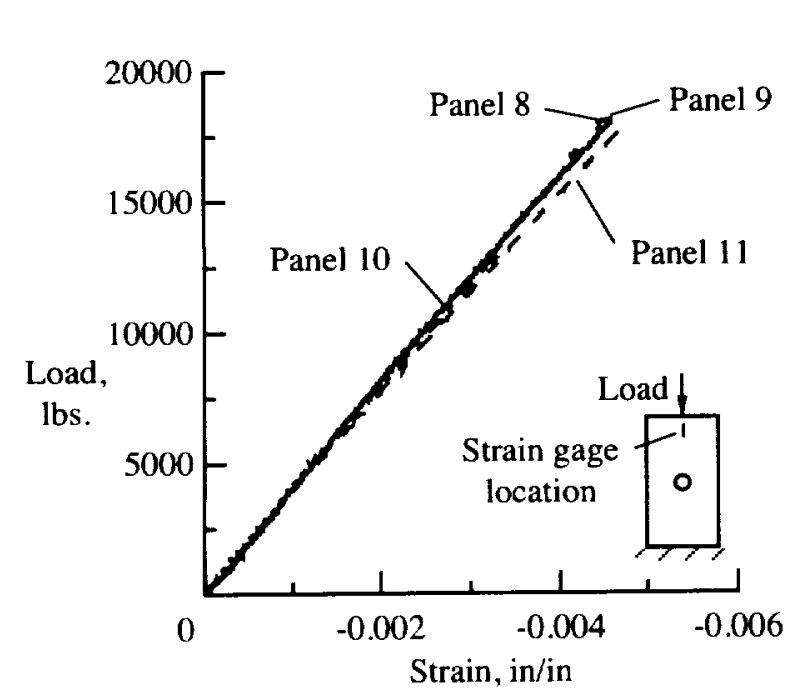

Fig.19. Axial surface strain results for Panels 8-11.

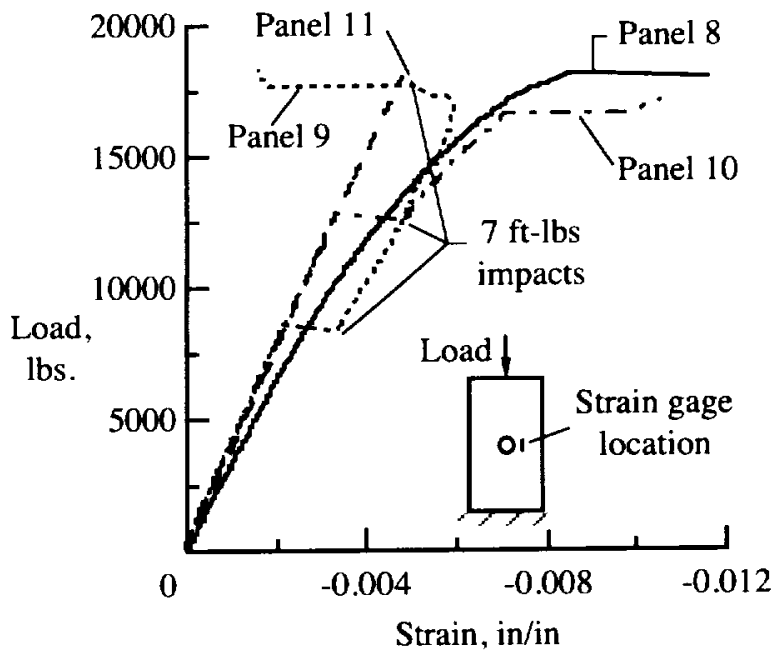

Fig. 20. Axial surface strain results for Panels 8-11. 
